Article

\title{
Study on the value of $\mathrm{C} 1 \mathrm{q}$ in the diagnosis of Esophageal cancer
}

\author{
Cai Xin ${ }^{1}$, Li Huan ${ }^{1}$, Chen Juanjuan ${ }^{1}$, Tang Dongling ${ }^{1}$, Zhang Pingan ${ }^{*}$ \\ ${ }^{1}$ Department of Clinical laboratory, Renmin Hospital of Wuhan University, Hubei Province, China \\ * Correspondence: zhangpingan927@163.com; +86 1397119 6429; 430060
}

\begin{abstract}
Background: Esophageal cancer was hardly diagnosed in early stage, and more potential biomarkers should be found. Methods: 252 patients and normal controls which recruited in Renmin Hospital of Wuhan University, were divided into esophageal carcinoma group (105 cases), disease control group (75 cases) and the control group of healthy people (72 cases). Moreover, TISIDB and GEPIA databases were used to investigate the different expression of EC and normal tissues, and explore the roles of $\mathrm{C} 1 \mathrm{q}$ in tumor-immune system interactions in EC. Results: The concentration of serum C1q in EC group is $196.8(180 \sim 219.4) \mathrm{mg} / \mathrm{L}$, which is higher than the level of DC [178.10(153.70 200.85) mg/L] and HC [183.00(167.75 201.00) mg/L] $(P<0.05)$. A higher expression level of C1q was observed in III and IV grades [214(192 237.3) $\mathrm{mg} / \mathrm{ml}]$ than grades I and II [180.95(172.03 193.85) $\mathrm{mg} / \mathrm{L}]$ $(P<0.05)$. C1q was positively correlated with eosinophils, active CD8 T cells, myeloid derived suppressor cells, natural killer cells, monocytes and macrophages $(r=0.373 ; r=0.659 ; r=0.846 ; r=0.760 ; r=0.499 ; r=0.757$; $P<0.05)$. Conclusion: The concentrations of $\mathrm{C} 1 \mathrm{q}$ increased in $\mathrm{EC}$ and related to the severity of EC, which had potential value of diagnosis of EC. There were correlations in C1q and tumor-infiltrating lymphocytes.
\end{abstract}

Keywords: C1q; Biomarker; Esophageal cancer; Diagnosis; Tumor

\section{Background}

Esophageal cancer (EC) is the seventh most common cancer and the sixth in mortality in the whole world [1]. There are two most common histologic subtypes, squamous cell carcinoma (SCC) and adenocarcinoma (AC), with quite different etiologies. SCC and AC account for up to $90 \%$ and $20 \%$ of all ECs, respectively. Excess body weight, gastroesophageal reflux disease and Barrett's esophagus are regarded as the key risk factor. Besides, dietary components play a role, especially in lower income countries. Overt clinical symptoms, such as dysphagia and odynophagia, are usually present at a later stage, which makes early diagnosis of EC difficult ${ }^{[2]}$. As a result, mass screening strategies for EC are highly desirable. Though endoscopy as the gold standard in diagnosing EC, many patients refuse this way for cancer surveillance ${ }^{[3]}$. Comparing with endoscopy, blood biomarkers are easier accepted by patients, which have lower price and non-invasive inspection method. Squamous cell associated antigen, carcinoembryonic antigen and carbohydrate antigen 50 are commonly used for the diagnosis of EC, but the diagnostic efficiency still needs to be improved ${ }^{[4,5,6]}$. For these reasons, blood markers are more suitable for mass screening than endoscopy and new blood biomarkers are urgent to be found.

The complement system which plays key role in innate immunity is regarded to kill tumor cells. C1q, C3derived fragments, and C5a which belongs to complement system are recognized as major molecule in control of tumor growth ${ }^{[7]}$. C1q was first discovered in the early 1960 s as the initiation component of the classical complement pathway which plays important part in autoimmunity ${ }^{[8,9]}$. This molecule is a glycoprotein assembled from 18 polypeptide chains which can be divided into 3 types ${ }^{[10]}$. Two functional domains of $\mathrm{C} 1 \mathrm{q}$ are globular regions and collagen-like regions, respectively ${ }^{[11]}$. As time goes by, more functions of $\mathrm{C} 1 \mathrm{q}$ are gradually discovered. A recent report shows that $\mathrm{C} 1 \mathrm{q}$ plays important role in cancer-immunity step as inhibitor of antitumor Th1 response and initiator of anti-tumor immunity ${ }^{[7]}$. Tumor cells hijack complement $\mathrm{C} 1 \mathrm{q}$ which produced by macrophages to 
promote tumor growth ${ }^{[12]} . \mathrm{Clq}$ is related to immunodeficiency, an article reports that patients with $\mathrm{C} 1 \mathrm{q}$ deficiency were more likely suffer from Systemic Lupus Erythematosus ${ }^{[13]}$. However, there is no research report about $\mathrm{C} 1 \mathrm{q}$ in esophageal cancer. This article will mainly analyze the concentration of $\mathrm{C} 1 \mathrm{q}$ in the serum of patients with esophageal cancer and relationship with inflammatory effects.

\section{Materials and Methods}

\subsection{Bioinformatics Analysis}

GEPIA (Gene Expression Profiling Interactive Analysis) (http://www.oncolnc.org/) has always been a valuable and highly cited resource for gene expression analysis based on tumor and normal samples from TCGA and GTEx databases. Contains RNA sequencing data based on 9,736 tumor samples and 8,587 normal samples from TCGA and GTEx databases.

TISIDB (http://cis.hku.hk/TISIDB) is a web portal for tumor and immune system interaction, which integrates multiple heterogeneous data types. It includes several data of 30 cancer types from TCGA and public databases.

\subsection{Research Object Selection}

All patients were recruited in the department of oncology and physical examination center, Renmin Hospital of Wuhan University, Hubei Province, China from July 2020 to July 2021. According to the Clinical Practice Guidelines of the ESMO ${ }^{[14]}$, all 252 patients and normal controls were divided into esophageal carcinoma (EC) group (105 cases), disease control (DC) group (75 cases) and the control group of healthy people (HC) (72 cases). We defined reflux esophagitis as disease control group. All esophageal carcinoma patients were confirmed by esophageal cancer pathological examination, endoscopy and positron emission tomography (PET)-CT. Exclusion criteria for included cases: (1) Exclude malignant tumors other than Esophageal carcinoma. (2) Exclude diseases such as severe diabetes, hyperthyroidism, and cardiovascular disease. (3) Exclude pregnant patients. All control group of healthy people tested for all biochemical tests were normal.

This study has been reviewed and approved by the Medical Ethics Review Committee of Renmin Hospital, Wuhan University. According to the requirements of the Medical Ethics Review Committee of Renmin Hospital, Wuhan University, all the included persons agreed and signed the informed consent form.

\subsection{Data Collection}

All data were collected from the Department of Clinical Laboratory, Renmin Hospital of Wuhan University. The concentration of all indexes were the first laboratory test results after admission. Serum complement C1q, Alanine aminotransferase (ALT), aspartate aminotransferase (AST), creatinine (CRE) and uric acid (UA) were detected by ADVIA 2400 biochemical analyzer (Siemens, Germany) and related reagents. Immunoturbidimetry was used for the detection of serum complement $\mathrm{C} 1 \mathrm{q}$, and the $\mathrm{C} 1 \mathrm{q}$ reagent was purchased from Shanghai Beijia biochemical reagent Co., Ltd. The normal reference value of complement C1q level in serum was $197.00 \pm 40.00$ $\mathrm{mg} / \mathrm{L}$. The number of platelets (PLT), neutrophils (NE), monocytes (MO) and lymphocytes (LY) were analyzed by Sysmex XN-9000 automatic blood cell analyzer (Sysmex, Japan).

\subsection{Statistical Analysis}

The experimental data was analyzed using SPSS version 20.0 (IBM Corp, NY) and MedCal 15.2.2 (Ostend, Belgium), GraphPad Prism 6.0 (GraphPad Software, Inc, La Jolla, CA) was used for image rendering. The measurement data uses the single-sample Kolmogorov-Smirnov method to test whether the data of each group conforms to normality, the normal distribution data is represented by $\bar{\chi} \pm \mathrm{s}$, the comparison between multiple groups is performed by analysis of variance, and the further pairwise comparison is performed by LSD- $t$ test. The skew distribution data is represented by $\mathrm{M}\left(\mathrm{P}_{25} \sim \mathrm{P}_{75}\right)$, the comparison between multiple groups uses the Kruskal-Wallis $\mathrm{H}$ test, the Nemenyi test was used for pairwise comparison. $P<0.05$ indicates that the difference is statistically significant. Spearman correlation coefficient is used to express the correlation between two sets of data.

\section{Result}

\subsection{Study Population}

The clinical data of all subjects are shown in Table 1. The levels of ALT, AST, CRE and UA have no significate 
difference $(P>0.05)$. The gender and ages of each group also have no difference in statistics $(P>0.05)$, while PLT, NE, LY, MO are higher than DC and $\mathrm{HC}(P<0.05)$.

Table1. Clinical characteristics of the participants.

\begin{tabular}{|c|c|c|c|c|}
\hline & EC (105cases) & DC ( 75 cases $)$ & HC (72cases) & $P$ \\
\hline $\begin{array}{l}\text { Gender } \\
\text { (Male/Female) }\end{array}$ & $64 / 41$ & $34 / 41$ & $40 / 32$ & 0.115 \\
\hline Age (years) & 63.3 & 56.6 & 60.7 & 0.517 \\
\hline ALT(U/L) & $16.00(11.00 \sim 21.00)$ & $17.00(12.50 \sim 22.50)$ & $18.00(14.75 \sim 24.25)$ & 0.057 \\
\hline AST(U/L) & $19.00(16.00 \sim 24.00)$ & $19.00(17.00 \sim 23.00)$ & $21.00(18.00 \sim 24.00)$ & 0.205 \\
\hline $\mathrm{CRE}(\mu \mathrm{mol} / \mathrm{L})$ & $63.00(54.00 \sim 75.00)$ & $59.00(53.00 \sim 72.00)$ & $58.50(51.75 \sim 69.25)$ & 0.229 \\
\hline $\mathrm{UA}(\mu \mathrm{mol} / \mathrm{L})$ & $313.50(263.50 \sim 390.25)$ & $313.50(250.25 \sim 380.00)$ & $297.50(258.75 \sim 347.75)$ & 0.281 \\
\hline $\operatorname{PLT}\left(10^{9} / \mathrm{L}\right)$ & $179.00(138.00 \sim 228.00)$ & $217.0(179.5 \sim 253.5)$ & $214.00(186.00 \sim 262.50)$ & $<0.05$ \\
\hline $\mathrm{NE}\left(10^{9} / \mathrm{L}\right)$ & $4.41(3.10 \sim 6.97)$ & $3.29(2.60 \sim 4.27)$ & $3.47(2.92 \sim 3.80)$ & $<0.05$ \\
\hline $\mathrm{LY}\left(10^{9} / \mathrm{L}\right)$ & $0.88(0.63 \sim 1.22)$ & $1.65(1.33 \sim 2.08)$ & $1.90(1.61 \sim 2.32)$ & $<0.05$ \\
\hline MO $\left(10^{9} / \mathrm{L}\right)$ & $0.49(0.32 \sim 0.66)$ & $0.40(0.32 \sim 0.50)$ & $0.43(0.34 \sim 0.50)$ & $<0.05$ \\
\hline $\mathrm{C} 1 \mathrm{q}(\mathrm{mg} / \mathrm{L})$ & $196.8(180 \sim 219.4)$ & $178.10(153.70 \sim 200.85)$ & $183.00(167.75 \sim 201.00)$ & $<0.05$ \\
\hline $\begin{array}{l}\text { Grade 1(I、II) } \\
\text { (case) }\end{array}$ & 40 & $\mathrm{~N}$ & $\mathrm{~N}$ & \\
\hline $\begin{array}{l}\text { Grade } 2(\mathrm{III} \text { 、 } \\
\text { IV) (case) }\end{array}$ & 65 & $\mathrm{~N}$ & $\mathrm{~N}$ & \\
\hline
\end{tabular}

\subsection{Elevated Expression of C1q mRNA in EC}

We investigated the differential expression of $\mathrm{C} 1 \mathrm{q}$ using the GEPIA databases. In GEPIA, C1q mRNA expression between tumors and their paired normal tissues across 32 TCGA cancer types were compared. C1q mRNA showed differences in all 17 types cancers. (Figure 1.A) The difference of C1q mRNA expression in esophageal cancer tissue and adjacent tissue was statistically significant. $(P<0.05)$ (Figure 1.C) In different stages, the expression of C1q mRNA was statistically significant. $(\operatorname{Pr}=0.0132)$ (Figure 1.B) 


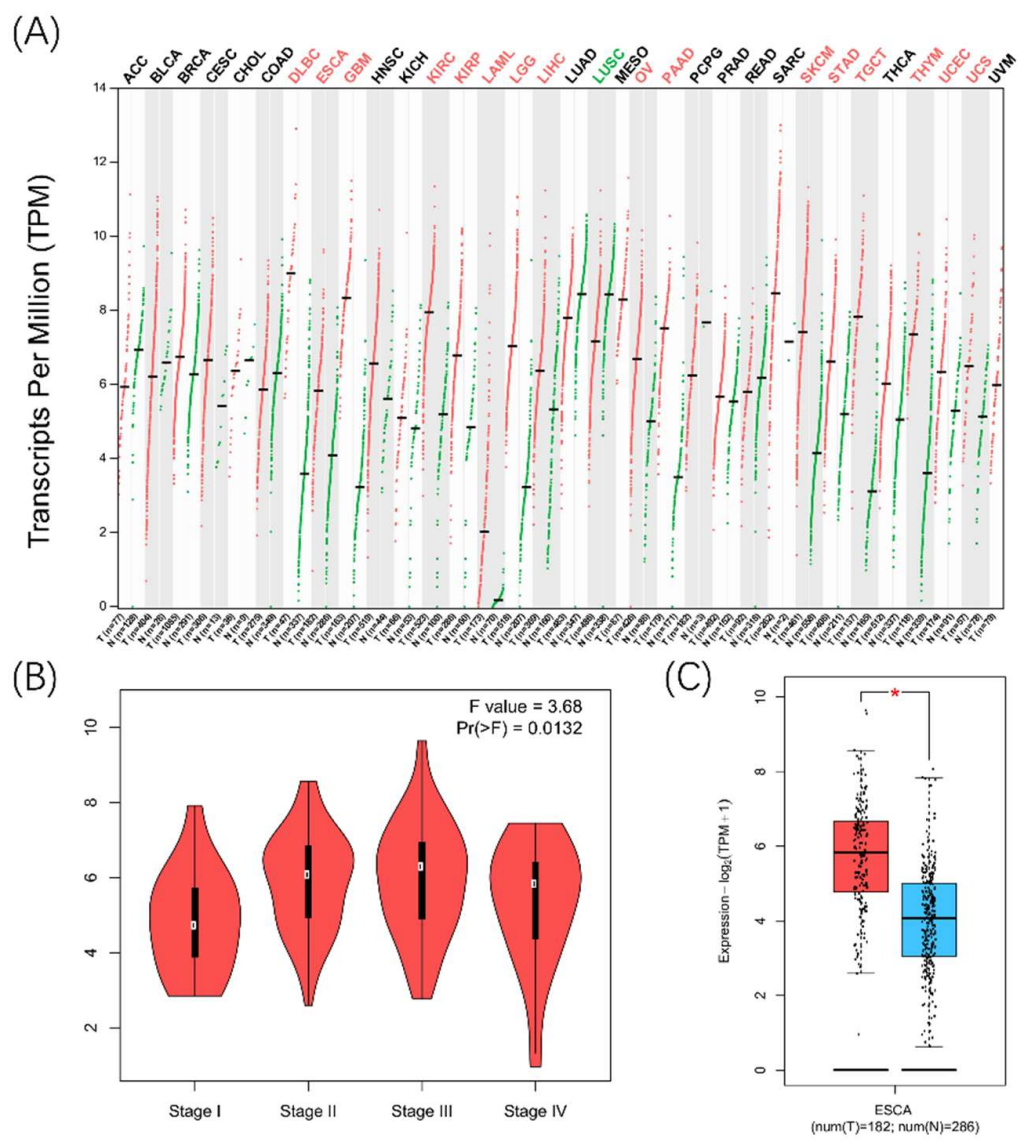

Figure 1. C1q mRNA expression is elevated in EC. (A)The expression of C1q varied among different tissues and tumors across TCGA cancer types from GEPIA, and the difference was significant in EC. (B)The level of C1q mRNA in different grades is different statistically. (C)The level of $\mathrm{C} 1 \mathrm{q}$ mRNA is higher than in normal tissues from GEPIA; $* \mathrm{P}<0.05$

\subsection{Elevated Expression of Serum C1q in ESCA Group}

To further validate these results, we test the concentrations of $\mathrm{C} 1 \mathrm{q}$ in serum of all patients. As shown in Table 1, the levels of C1q were 196.8(180 219.4) $\mathrm{mg} / \mathrm{L}, 178.10(153.70 \sim 200.85) \mathrm{mg} / \mathrm{L}$ and 183.00(167.75 201.00) $\mathrm{mg} / \mathrm{L}$ in EC group, $\mathrm{DC}$ group and $\mathrm{HC}$ group respectively. $\mathrm{C} 1 \mathrm{q}$ expressed higher in $\mathrm{EC}$ patients than disease control group and $\mathrm{HC}$ group $(P<0.05)$ (Figure2.A). We investigated the difference of $\mathrm{C} 1 \mathrm{q}$ in several $\mathrm{EC}$ samples of different $\operatorname{grades}(P<0.05)$ (Figure2.B). A higher expression level of C1q was observed in III and IV grades [214(192 237.3) $\mathrm{mg} / \mathrm{ml}]$ than grades I and II $[180.95(172.03 \sim 193.85) \mathrm{mg} / \mathrm{L}](P<0.05)$.
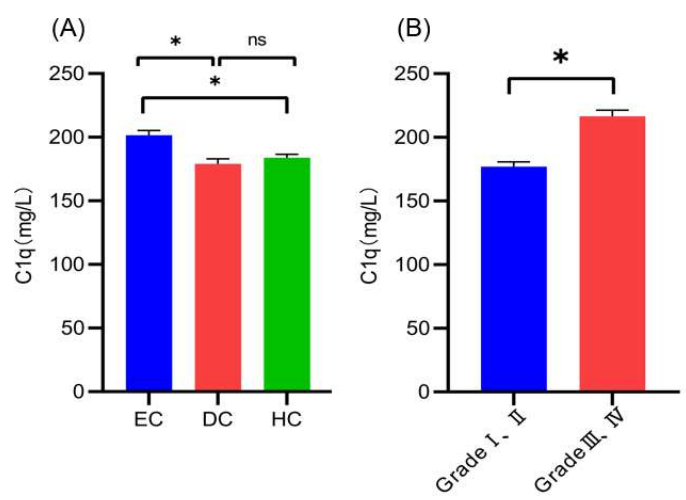

Figure 2. Serum C1q elevated in EC. (A)Serum C1q elevated in EC than DC and HC. (B)Serum C1q elevated in higher grades; 


\subsection{The Regulation of Immune Molecules by C1q}

$\mathrm{Clq}$ mediates a series of immunoregulatory functions which are regarded as key points in autoimmunity. Consequently, we explored whether C1q related to immune infiltration using TISIDB databases. We found that C1q expression was correlated with several kinds of tumor-infiltrating lymphocytes (TILs) in ESCA patients in TISIDB databases. TILs were shown great correlation with $\mathrm{C} 1 \mathrm{q}$, that included eosinophils (Spearman: $\mathrm{r}=0.373, P=2.06 \mathrm{e}-$ 07), active CD8 T cells (Spearman: $\mathrm{r}=0.659, P<2.2 \mathrm{e}-16$ ), myeloid derived suppressor cells (MDSC; Spearman: $\mathrm{r}$ $=0.846, P<2.2 \mathrm{e}-16]$, natural killer cells (NK; Spearman: $\mathrm{r}=0.76, P<2.2 \mathrm{e}-16)$, monocytes (Spearman: $\mathrm{r}=0.499$, $P<2.2 \mathrm{e}-16$ ), and macrophages (Spearman: $\mathrm{r}=0.757, P<2.2 \mathrm{e}-16$ )(Figure3).

(A)
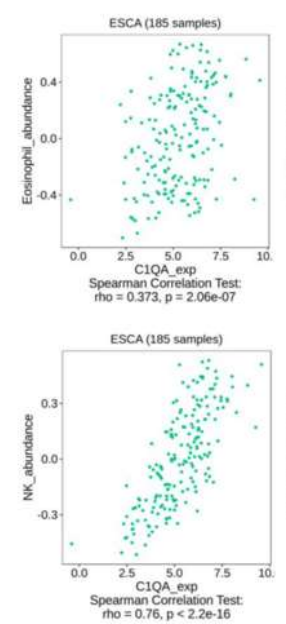
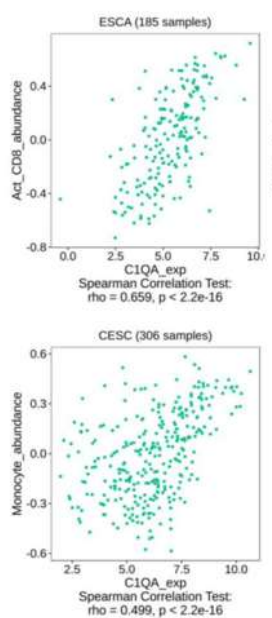
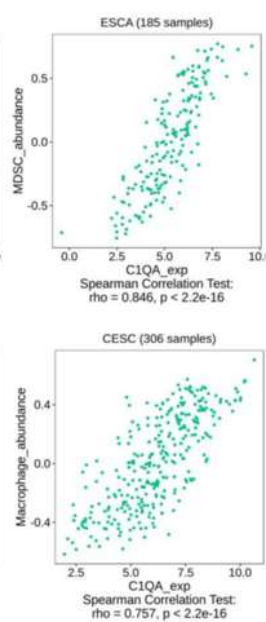

(B)

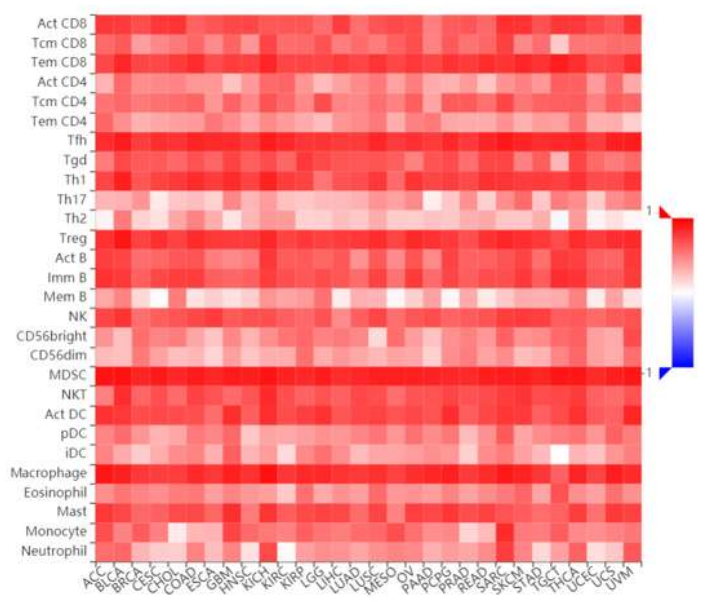

Figure 3. The correlation of $\mathrm{C} 1 \mathrm{q}$ and immune cells. (A)The correlation of $\mathrm{C} 1 \mathrm{q}$ and eosinophils, active CD8 T cells, myeloid derived suppressor cells, natural killer cells, monocytes, macrophages. (B) The correlation between PLXND1 expression and TILs in pancancer.

\subsection{Correlation Analysis of PLT, NE, LY, MO and C1q in EC}

As shown in Table 1, the levels of PLT and LY were lowest in EC group than DC group and HC group respectively. The level of NE was highest in EC groups (Figure 4). There was no correlation between C1q and anyone of those.
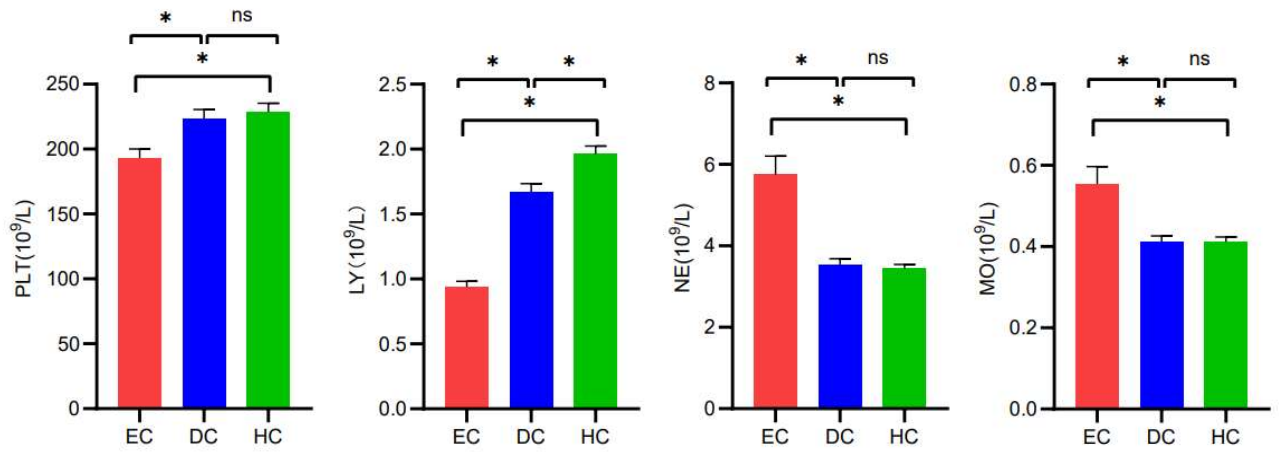

Figure 4. The level of PLT, NE, LY and MO in EC, DC and HC respectively; ${ }^{*} P<0.05$

\section{Discussion}

EC is the sixth most common cause of cancer death worldwide, which cause a huge global health challenge. Most patients with EC were discovered in advanced stages, and had adverse therapeutic effect. The common treatments were chemotherapy, chemoradiotherapy and surgical resection ${ }^{[15,16]}$. Reflux disease is associated with an increased risk of esophagitis, esophageal strictures, Barrett esophagus, and esophageal adenocarcinoma, and it has the similar symptoms to EC ${ }^{[17,18]}$. Using endoscopy can distinguish EC from reflux disease, though some 
patients refuse this way to check their esophagus ${ }^{[19]}$.As a result, a blood biomarker which can help to diagnose EC from reflux disease come to be important.

Our study showed that $\mathrm{Clq}$ expressed higher in serum of EC patients which indicate that C1q may have potential diagnosis of EC. Further, along with the growth of the grades, the concentrations of C1q were much higher which indicated that C1q may become a warning signal of progression of EC. Besides, PLT and lymphocytes expressed differently in EC from HC which indicated that inflammatory cells may play key role in EC. Although $\mathrm{C} 1 \mathrm{q}$ has no correlation with inflammatory cells in serum, tumor-infiltrating lymphocytes were correlated with C1q. The level of $\mathrm{Clq}$ in serum is elevated in patients with atherosclerosis and acute ischemic stroke, and a similar observation has been documented for glimoas and sepsis ${ }^{[20,21,22,23]}$. Although it was observed reduced in patients with multiple myeloma ${ }^{[24]}$. In this study, we showed that for the first time that C1q elevated in EC, and rose with evaluation of grades. It should be noted that different cancer cells respond to $\mathrm{C} 1 \mathrm{q}$ in different ways, and it is a proor anti-tumorigenic factor have not been confirmed yet. Hong et al. reported that C1q active the tumor suppressor WW-domain containing oxidoreductase (WOX1) to affect growth procession and apoptosis of human prostate cells ${ }^{[25]}$. C1q can promote adhesion, proliferation and migration of mice melanoma cells which indicated that C1q may play a role as tumor-promoting factor in cancers, which by complement dependent way or not ${ }^{[26]}$. Yuri et al. reported that $\mathrm{C} 1 \mathrm{q}$ express higher in normal tissue than in Barrett's esophagus specimens and specimens with adenocarcinoma [27]. We speculate that blood circulating C1q may be different from C1q expressed in tissues.

A great blood biomarker of cancer should possess several features, such as high sensitivity and can be tested in early stage ${ }^{[28,29]}$. However, such a perfect biomarker has not been found. As a result, the combination of different blood biomarkers come to be important. Nowadays, CEA is widely used in lab to diagnose EC, and its sensitivity ranged from $8 \%$ to $70 \%$, specificity ranged from $57 \%$ to $100 \%{ }^{[30]}$. Meanwhile, SCC and Cyfra $21-1$ also commonly used for diagnosis. Our findings may be useful in adding a new biomarker to potential circulating blood molecules for detecting EC. Because we examined only 252 patients, our results may have due to chance. The results must be confirmed in a larger study. Besides, the molecular mechanism of C1q in EC should be research in further study.

In summary, our study found that the concentrations of serum C1q in patients with EC is higher than patients with reflux esophagitis and healthy people, and it elevated with growth of grades, which may have potential to diagnose EC in early stage. Besides, C1q may play a role in inflammatory effects, which should be explored further. We suggest that scholars can focus on molecular mechanism of C1q in EC.

\section{Author contributions statement:}

Conceptualization, C, X. and L, H.; methodology, C, X.; software, L, H.; validation, C, J.J. and T, D.L.; formal analysis, C, X.; investigation, Z, P.A.; resources, Z, P.A.; writing —original draft preparation, C, X.; writing-review and editing, Z, P.A. All authors have read and agreed to the published version of the manuscript.

\section{Funding:}

This research was funded by the National Natural Science Foundation of China, grant number 81773444 .

\section{Acknowledgments:}

We would like to thank Tang Dongling (Renmin Hospital of Wuhan University) for excellent technical support.

\section{Institutional Review Board Statement:}

The trial was conducted in accordance with the Declaration of Helsinki (as revised in 2013). The study has been reviewed and approved by the Medical Ethics Review Committee of Renmin Hospital, Wuhan University and informed consent was taken from all individual participants.

\section{Informed Consent Statement:}

Informed consent was obtained from all subjects involved in the study.

\section{Data Availability Statement:}

Parts of the datasets used and/or analyzed during the current study are available from the corresponding author on reasonable request. The other part of the datasets is available from GEPIA (http://gepia2.cancer-pku.cn/) and TISIDB 
(http://cis.hku.hk/TISIDB) which offer free public datasets.

\section{Acknowledgments:}

We would like to thank the National Natural Science Foundation of China for excellent technical supp ort.

\section{Conflicts of Interest:}

The authors declare that they have no competing interests, financial competing interests and non-fina ncial competing interests.

\section{Reference:}

[1] Sung, H.; Ferlay, J.; Siegel, R. L.; Laversanne, M.; Soerjomataram, I.; Jemal, A.; Bray, F. Global Cancer Statistics 2020: GLOBOCAN Estimates of Incidence and Mortality Worldwide for 36 Cancers in 185 Countries, CA Cancer J Clin, 2021 May;71(3):209-249.

[2] Ferlay, J.; Colombet, M.; Soerjomataram, I.; Mathers, C.; Parkin, D. M.; Piñeros, M.; Znaor, A.; Bray, F. Estimating the global cancer incidence and mortality in 2018: GLOBOCAN sources and methods. Int J Cancer, 2019 Apr 15;144(8):1941-1953.

[3] Visaggi, P.; Barberio, B.; Ghisa, M.; Ribolsi, M.; Savarino, V.; Fassan, M.;Valmasoni, M.; Marchi, S.; de Bortoli, N.; Savarino, E. Modern Diagnosis of Early Esophageal Cancer: From Blood Biomarkers to Advanced Endoscopy and Artificial Intelligence, Cancers (Basel), 2021 Jun 24;13(13):3162.

[4] Cao, X.; Zhang, L.; Feng, G. R.; Yang, J.; Wang, R. Y.; Li, J.; Zheng, X. M.; Han, Y. J. Preoperative Cyfra21-1 and SCC-Ag serum titers predict survival in patients with stage II esophageal squamous cell carcinoma, J Transl Med, 2012 Sep 21;10:197.

[5] Zhang, H. Q.; Wang, R. B.; Yan, H. J.; Zhao, W.; Zhu, K. L.; Jiang, S. M.; Hu, X. G.; Yu, J. M. Prognostic significance of CYFRA21-1, CEA and hemoglobin in patients with esophageal squamous cancer undergoing concurrent chemoradiotherapy, Asian Pac J Cancer Prev,2012;13(1):199-203.

[6] Ikeguchi, M.; Kouno, Y.; Kihara, K.; Suzuki, K.; Endo, K.; Nakamura, S.; Sawada, T.; Shimizu, T.; Matsunaga, T.; Fukumoto, Y.; Saito, H. Evaluation of prognostic markers for patients with curatively resected thoracic esophageal squamous cell carcinomas, Mol Clin Oncol, 2016 Dec;5(6):767-772.

[7] Pio, R.; Ajona, D.; Ortiz-Espinosa, S.; Mantovani, A.; Lambris, J. D. Complementing the Cancer-Immunity Cycle, Front Immunol, 2019 Apr 12; 10:774.

[8] LEPOW, I. H.; NAFF, G. B.; TODD, E. W.; PENSKY, J.; HINZ, C. F. Chromatographic resolution of the first component of human complement into three activities. J Exp Med. 1963 Jun 1;117(6):983-1008.

[9] NAFF, G. B.; PENSKY, J.; LEPOW, I. H. THE MACROMOLECULAR NATURE OF THE FIRST COMPONENT OF HUMAN COMPLEMENT. J Exp Med. 1964 Apr 1;119(4):593-613.

[10] Reid, K. B.; Porter, R. R. Subunit composition and structure of subcomponent C1q of the first component of human complement. Biochem J. 1976 Apr 1;155(1):19-23.

[11] Hughes-Jones, N. C.; Gardner, B. Reaction between the isolated globular sub-units of the complement component C1q and IgG-complexes. Mol Immunol. 1979 Sep;16(9):697-701.

[12] Roumenina, L. T.; Daugan, M. V.; Noé, R.; Petitprez, F.;Vano, Y. A.; Sanchez-Salas, R.; Becht, E.; Meilleroux, J.;Clec'h, B. L.; Giraldo, N. A.; et al. Tumor Cells Hijack Macrophage-Produced Complement C1q to Promote Tumor Growth. Cancer Immunol Res. 2019 Jul;7(7):1091-1105.

[13] van Schaarenburg, R. A.; Schejbel, L.; Truedsson, L.; Topaloglu, R.; Al-Mayouf, S. M.; Riordan, A.; Simon, A.; Kallel-Sellami, M.; Arkwright, P. D.; Åhlin, A.; Hagelberg, S.; et al. Marked variability in clinical presentation and outcome of patients with C1q immunodeficiency. J Autoimmun. 2015 Aug;62: 39-44.

[14] Muro, K.; Lordick, F.; Tsushima, T.; Pentheroudakis, G.; Baba, E.; Lu, Z.; Cho, B. C.; Nor, I. M.; Ng, M.; Chen, L. T.; et al. Pan-Asian adapted ESMO Clinical Practice Guidelines for the management of patients with metastatic oesophageal cancer: a JSMO-ESMO initiative endorsed by CSCO, KSMO, MOS, SSO and TOS. Ann Oncol. 2019 Jan 1;30(1):34-43. 
[15] Smyth, E. C.; Lagergren, J.; Fitzgerald, R. C.; Lordick, F.; Shah, M. A.; Lagergren, P.; Cunningham, D. Oesophageal cancer. Nat Rev Dis Primers. 2017 Jul 27;3:17048.

[16] Shah, M. A.; Kennedy, E. B.; Catenacci, D. V.; Deighton, D. C.; Goodman, K. A.; Malhotra, N. K.; Willett, C.; Stiles, B.; Sharma, P.; Tang, L.; et al. Treatment of Locally Advanced Esophageal Carcinoma: ASCO Guideline. J Clin Oncol. 2020 Aug 10;38(23):2677-2694.

[17] Maret-Ouda, J.; Markar, S. R.; Lagergren, J. Gastroesophageal Reflux Disease: A Review. JAMA. 2020 Dec 22;324(24):2536-2547.

[18] Katzka, D. A.; Kahrilas, P. J. Advances in the diagnosis and management of gastroesophageal reflux disease. BMJ. 2020 Nov 23;371:m3786.

[19] Dekker, E.; Houwen, B.; Puig, I.; Bustamante-Balén, M.; Coron, E.; Dobru, D. E.; Kuvaev, R.; Neumann, H.; Johnson, G.; Pimentel-Nunes, P.; et al. Curriculum for optical diagnosis training in Europe: European Society of Gastrointestinal Endoscopy (ESGE) Position Statement. Endoscopy. 2020 Oct;52(10):C10.

[20] Spivia, W.; Magno, P. S.; Le, P.; Fraser, D. A. Complement protein C1q promotes macrophage antiinflammatory M2-like polarization during the clearance of atherogenic lipoproteins. Inflamm Res. (2014) 63:88593.

[21] Zhao, X.; Wang, C.; Pang, B.; Zhu, Y.; Zhang, Y. The Value of Serum Complement C1q in the Diagnosis of Acute Ischemic Stroke. Clin Lab. 2017 May 1;63(5):915-920.

[22] Mangogna, A.; Belmonte, B.; Agostinis, C.; Zacchi, P.; Iacopino, D. G.; Martorana, A.; Rodolico, V.; Bonazza, D.; Zanconati, F.; Kishore, U.; et al. Prognostic Implications of the Complement Protein C1q in Gliomas. Front Immunol. 2019 Oct 10;10:2366.

[23] Li, H.; Chen, J.; Hu, Y.; Cai, X.; Zhang, P. Elevated Serum C1q Levels in Children With Sepsis. Front Pediatr. 2021 Apr 26;9:619899.

[24] Yang, R.; Huang, J.; Ma, H.; Li, S.; Gao, X.; Liu, Y.; Shen, J.; Liao, A. Is complement Clq a pot ential marker for tumor burden and immunodeficiency in multiple myeloma? Leuk Lymphoma. 2019 Jul; 60(7):1812-1818.

[25] Hong, Q.; Sze, C. I.; Lin, S. R.; Lee, M. H.; He, R. Y.; Schultz, L.; Chang, J. Y.; Chen, S. J.; Bo ackle, R. J.; Hsu, L. J.; Chang, N. S. Complement C1q activates tumor suppressor WWOX to induce ap optosis in prostate cancer cells. PLoS One. 2009 Jun 1;4(6): e5755.

[26] Bulla, R.; Tripodo, C.; Rami, D.; Ling, G. S.; Agostinis, C.; Guarnotta, C.; Zorzet, S.; Durigutto, P.; Botto, M.; Tedesco, F. C1q acts in the tumour microenvironment as a cancer-promoting factor independently of complement activation. Nat Commun. 2016 Feb 1;7:10346.

[27] Bobryshev, Y. V.; Lu, J.; Lord, R. V. Expression of C1q complement component in Barrett's esophagus and esophageal adenocarcinoma. J Gastrointest Surg. 2010 Aug;14(8):1207-13.

[28] Lin, Y.; Qian, F.; Shen, L.; Chen, F.; Chen, J.; Shen, B. Computer-aided biomarker discovery for precision medicine: data resources, models and applications. Brief Bioinform. 2019 May 21;20(3):952-975.

[29] Califf R. M. Biomarker definitions and their applications. Exp Biol Med (Maywood). 2018 Feb;243(3):213221.

[30] Zhang, J.; Zhu, Z.; Liu, Y.; Jin, X.; Xu, Z.; Yu, Q.; Li, K. Diagnostic value of multiple tumor markers for patients with esophageal carcinoma. PLoS One. 2015 Feb 18;10(2):e0116951. 